
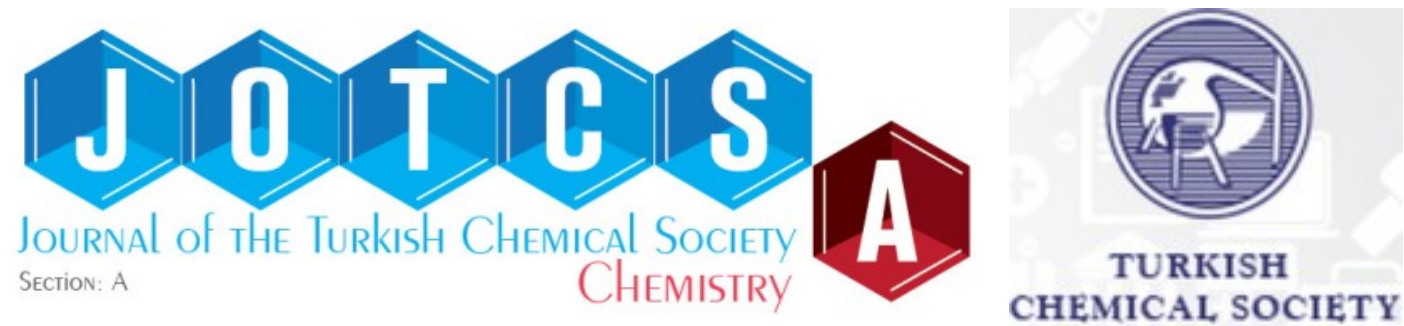

\title{
A Study on the Optoelectronic Parameters of 4-Chloromethyl-7-Hydroxy Coumarin in Various Solvents and Concentrations
}

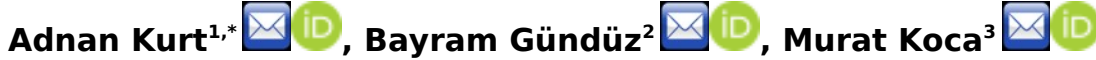 \\ ${ }^{1}$ Department of Chemistry, Faculty of Science and Arts, Adiyaman University, Adiyaman/Turkey \\ ${ }^{2}$ Department of Engineering Basic Sciences, Faculty of Engineering and Natural Sciences, Malatya Turgut \\ Özal University, Malatya, Turkey \\ ${ }^{3}$ Department of Pharm. Chemistry, Pharmacy Faculty, Adiyaman University, Adiyaman/Turkey
}

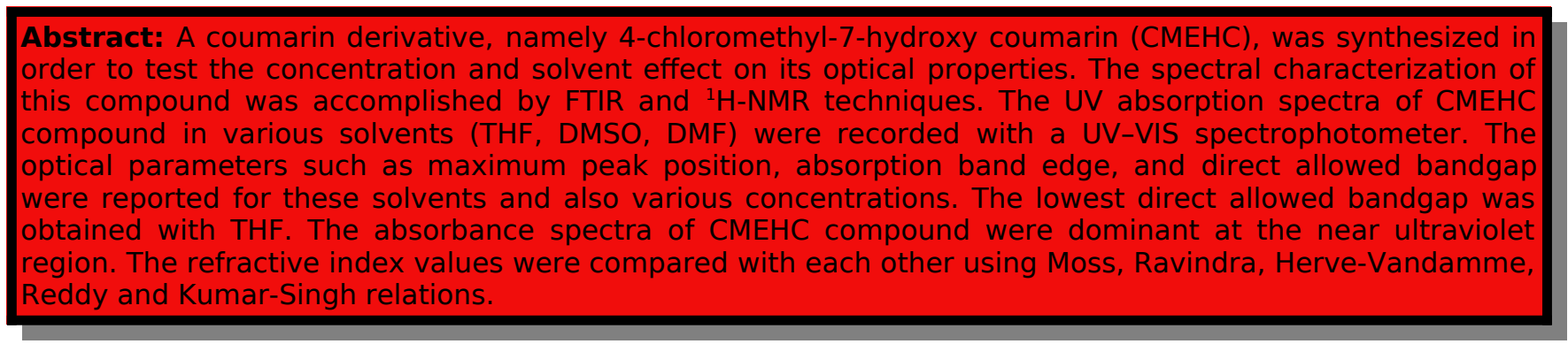

Keywords: Coumarin derivative, optoelectronic parameters, concentration and solvent effect, absorption band edge, optical bandgap, refractive index.

Submitted: March 04, 2020. Accepted: December 15, 2020.

Cite this: Kurt A, Gündüz B, Koca M. A Study on the Optoelectronic Parameters of 4-Chloromethyl-7Hydroxy Coumarin in Various Solvents and Concentrations. JOTCSA. 2021;8(1):155-62.

DOI: https://doi.org/10.18596/jotcsa.698612.

*Corresponding author: e-mail: akurt@adiyaman.edu.tr, Tel: +90416 2233800.

\section{INTRODUCTION}

As is well known, coumarins are important members of oxygen-containing heterocyclic compounds. They are included in the class of lactones containing benzopyrone skeletal framework (1). The chemical structure of the basic coumarin ring consisting of the combination of benzene and pyrone rings at second position of the pyrone carbonyl (2). Coumarins establish one of the major classes of naturally occurring compounds and are widely isolated from plants. The synthesis of these natural or novel synthetic coumarins and their derivatives with various functional groups in the laboratory are also possible (3). Especially, the characteristics of the main coumarin compounds vary considerably by connecting the appropriate components into them. Thus, they may be converted to more useful and relevant products in different fields of science and technology (4). Because of their $\pi$-conjugated structures, coumarins and derivatives exhibit significant and unique photophysical and spectroscopic properties (5). They have been extensively used in electronically, optically, and photonic applications such as organic light-emitting diodes (6), electroluminescence (7), fluorescent materials (8), nonlinear optical materials (9), photoalignment of liquid crystalline molecules (10), charge-transfer agents (11), two-photon absorption materials (12), organic-inorganic hybrid materials (13), and laser dyes (14).

Besides, the investigation of optical parameters of organic compounds is essential for many applications, as highlighted above. These compounds are usually characterized by their UVvisible absorption spectra (15) to measure some optical parameters such as refractive index, 
absorption band edge, optical bandgap, etc. (16-19). For this purpose, some papers have been published on the optical properties of coumarins $(2,5,20,21)$. In one of these studies, Tasior and coworkers (5) reported a review involved the synthesis mechanisms, comparison and analysis of linear optical properties and possible applications in the current technology of some r-expanded coumarins. Bai and coworkers (20) investigated the synthesis, characterization, optical properties and theoretical calculations of 6 -fluoro coumarin compound. They reported that it absorbed UV-VIS light at 319, 269, and $215 \mathrm{~nm}$ and exhibited blue-purple fluorescence emission at $416 \mathrm{~nm}$. Skowronski and coworkers (2) reported that the optical properties of coumarincontaining copolymers thin films by means of spectroscopic ellipsometry combined with transmittance measurements and atomic force microscopy. In another study reported by Rabahi and coworkers (21), the synthesis and optical properties of coumarins and iminocoumarins were investigated in different solvents by UV/vis absorption and fluorescence spectroscopy at room temperature. Ground-state and excited-state dipole moments were estimated from a solvatochromic shift and theoretical methods.

As it is explained above, although the optical properties of some coumarin compounds have been investigated, these properties are mainly focused on the investigation of transmittance or emission properties. Based on our literature knowledge, there are not enough works on the optical parameters such as the maximum peak position, absorption band edge, refractive index, and direct allowed bandgap reported for 4-chloromethyl-7-hydroxy coumarin. Therefore, we aim to investigate some optical parameters in different solvents and concentrations of a coumarin derivative compound, 4-chloromethyl-7-hydroxy coumarin. The obtained results show that 4-chloromethyl-7-hydroxy coumarin exhibits a semiconductor behavior and it may be an important candidate for many optoelectronic devices such as diodes, photo-diodes, and sensors.

\section{EXPERIMENTAL}

\section{Materials}<smiles>Oc1cccc(O)c1</smiles><smiles>CCOC(=O)CC(=O)CCl</smiles><smiles>O=c1cc(CCl)c2ccc(O)cc2o1</smiles>

Scheme 1. Synthesis of CMEHC compound.
Resorcinol (99\%), ethyl-4-chloroacetoacetate (95\%) and sulfuric acid $\left(\mathrm{H}_{2} \mathrm{SO}_{4}\right.$, ACS reagent, 95.0-98.0\%) were purchased from Sigma-Aldrich. The used solvents tetrahydrofuran (THF, anhydrous $\geq 99.9 \%$ ), $\mathrm{N}, \mathrm{N}$-dimethylformamide (DMF, anhydrous 99.8\%), dimethyl sulfoxide (DMSO, anhydrous $\geq 99.9 \%$ ) were also purchased from Sigma-Aldrich.

\section{Instrumental Techniques}

Proton nuclear magnetic resonance spectrum $\left({ }^{1} \mathrm{H}-\right.$ NMR) of the coumarin compound was recorded on a Bruker $300 \mathrm{Mhz}$ Ultrashield TM instrument at room temperature using deuterated DMSO solvent and TMS as an internal standard. The infrared characterization was carried out by a Perkin Elmer Spectrum 100 FTIR spectrometer with ATR accessory. The UV measurements of the CMEHC solutions for different solvents and molarities were recorded with a Shimadzu model UV-1800 spectrophotometer using a cylindrical bathtub (Hellma QS-100) in the wavelength 1100-190 nm at room temperature. The CMEHC compound samples weighed with an analytical balance (AND-GR-200 Series) were homogeneously dissolved in $12-\mathrm{mL}$ volumes of THF, DMF, and DMSO solvents. Besides, the solutions at different molarities of $28.65,0.358$, $0.054,0.013$, and $0.007 \mathrm{mM}$ of this compound were also prepared using the same amount of DMSO solvent (12 mL).

\section{Synthesis of 4-Chloromethyl-7-Hydroxy Coumarin (CMEHC)}

The synthesis of CMEHC was carried out according to the pathway reported in previous studies $(22,23)$. Briefly, CMEHC compound was synthesized as follows: Powdered resorcinol $(11.011 \mathrm{~g})$ and ethyl-4chloroacetoacetate $(16.459 \mathrm{~g})$ were dissolved in a $50-\mathrm{mL}$ beaker and this solution was added dropwise to $40 \mathrm{~mL}$ of concentrated sulfuric acid in a reaction balloon at the temperature of $0-5{ }^{\circ} \mathrm{C}$. The reaction mixture was stirred continuously on a magnetic stirrer for two hours. Then, the obtained dark brown solution was poured into the excess ice-cold water. Thus, the product of 4-chloromethyl-7-hydroxy coumarin (CMEHC) was precipitated as white sediments, filtered, and dried (Scheme 1). The yield of CMEHC synthesis reaction was found to be $81 \%$.

\section{RESULTS AND DISCUSSIONS}

Spectral Characterization
Figure 1 shows the FTIR spectrum of CMEHC in which the most characteristic bands are observed at $3286 \mathrm{~cm}^{-1}$ (-OH stretching vibration), $3092-3018 \mathrm{~cm}^{-1}$ and $2989-2880 \mathrm{~cm}^{-1}$ (aromatic and aliphatic $\mathrm{C}-\mathrm{H}$ 
stretching vibrations, respectively), $1694 \mathrm{~cm}^{-1}$ (lactone $\mathrm{C}=\mathrm{O}$ stretching in coumarin ring), $1621 \mathrm{~cm}^{-1}$ (lactone $\mathrm{C}=\mathrm{C}$ stretching) and $1605 \mathrm{~cm}^{-1}$ (aromatic $\mathrm{C}=\mathrm{C}$ stretching). ${ }^{1} \mathrm{H}-\mathrm{NMR}$ spectrum of $\mathrm{CMEHC}$ compound was shown in Figure 2. A singlet signal at $10.6 \mathrm{ppm}$ is attributed to $\mathrm{O}-\mathrm{H}$ proton in coumarin ring. The chemical shifts observed between 7.7 ppm and $6.7 \mathrm{ppm}$ are characteristics for aromatic $=\mathrm{CH}$ protons. The signal at $6.4 \mathrm{ppm}$ is also attributed to aliphatic $=\mathrm{CH}$ - proton in coumarin ring. The singlet signal for $-\mathrm{CH}_{2} \mathrm{Cl}$ protons is observed at the chemical shift $4.9 \mathrm{ppm}$. The signals at 3.3 and $2.5 \mathrm{ppm}$ are due to DMSO solvent.

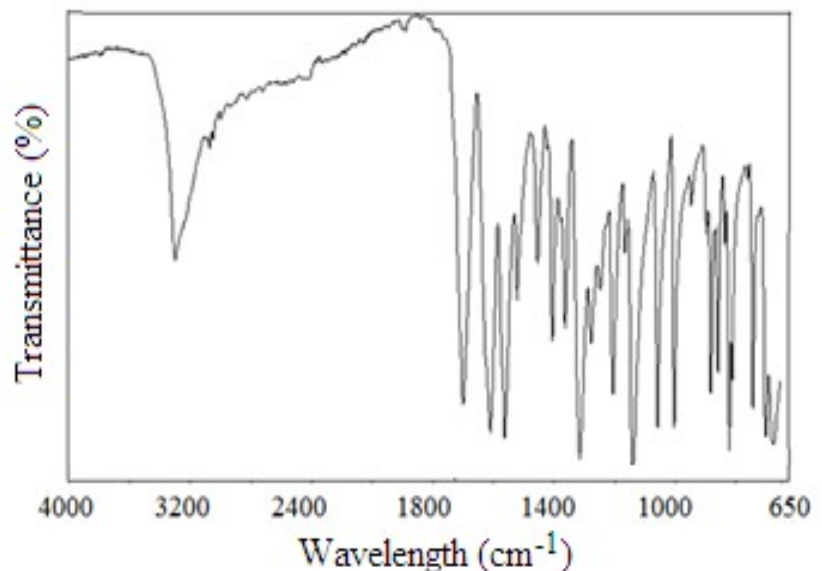

Figure 1. FTIR spectrum of CMEHC.

\section{Optical Properties}

Absorbance is the amount of light absorbed by a sample and is important in the determination of optical properties. Figure $3(a, b)$ indicates the

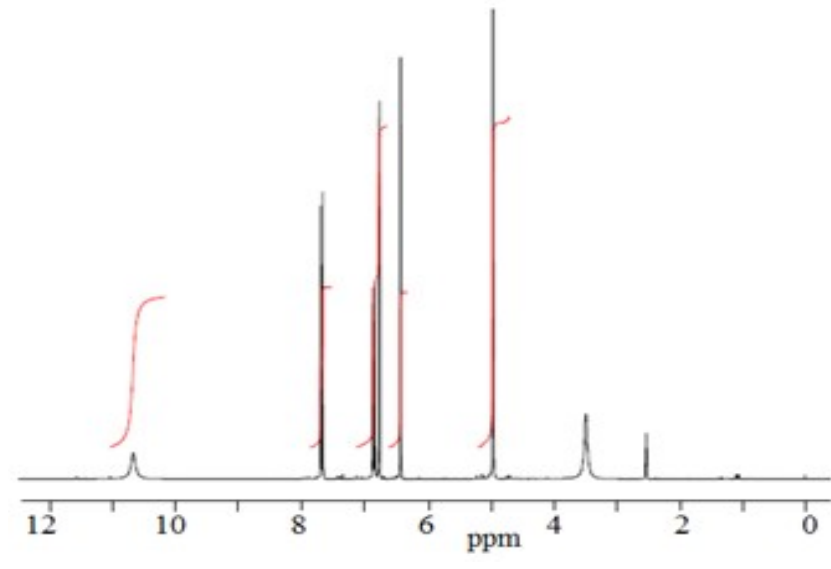

Figure 2. ${ }^{1} \mathrm{H}-\mathrm{NMR}$ spectrum of CMEHC compound.

absorbance spectra of the CMEHC coumarin compound for different solvents (THF, DMF, and DMSO) and different molarities using DMSO (28.65, $0.358,0.054,0.013$, and $0.007 \mathrm{mM})$, respectively.
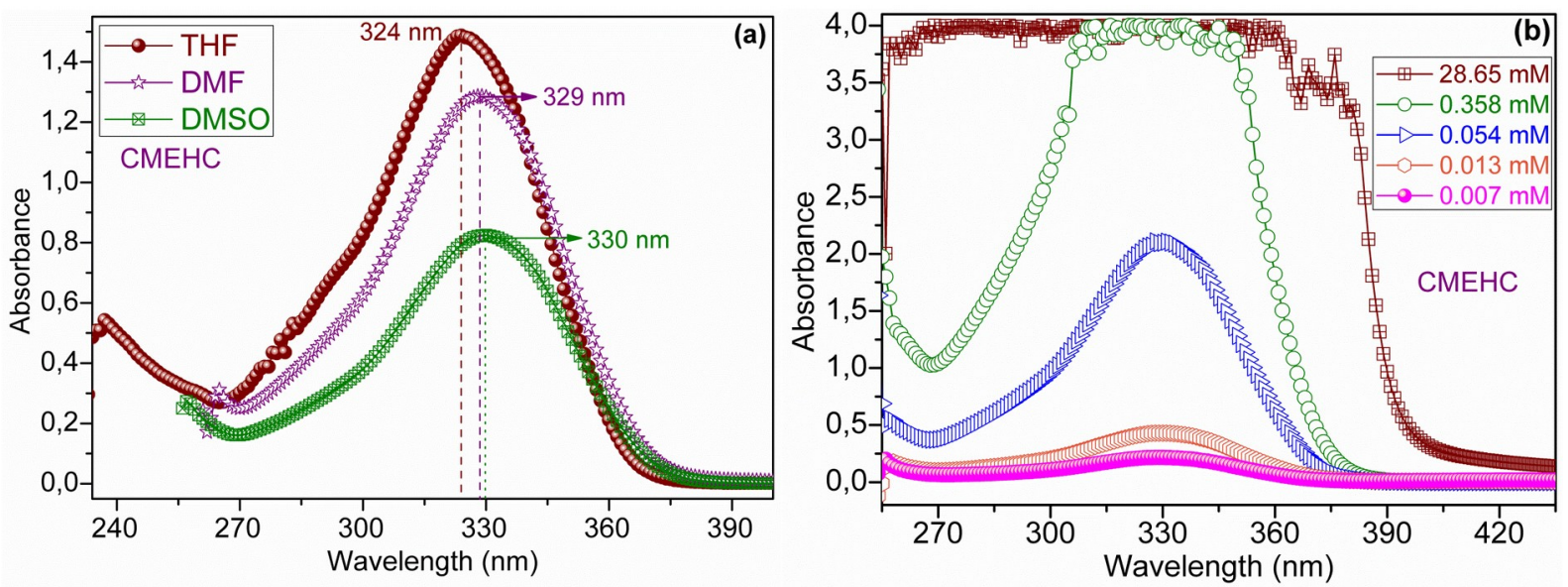

Figure 3. The absorbance spectra: (a) for THF, DMF and DMSO solvents and (b) for 28.65, 0.358, 0.054 0.013 and $0.007 \mathrm{mM}$ in DMSO.

As seen in Figure $3 \mathrm{a}, \mathrm{CMEHC}$ exhibits the maximum absorbance peaks at 324, 329 and $330 \mathrm{~nm}$ for THF, DMF and DMSO solvents, respectively. Obtained results show that the position of the maximum absorbance peak can be changed with the solvents, and also, the absorbance for THF solvent is the highest while the absorbance for DMSO solvent is the lowest. As seen in Figure 3b, the absorbance of the CMEHC has not been observed at higher molarities than $0.358 \mathrm{mM}$ and that decreases with decreasing molarity. The absorbance spectra of the CMEHC compound are dominant at the near ultraviolet (NUV) region. Besides, THF, DMF and DMSO have a significant effect on absorbance of CMEHC. 

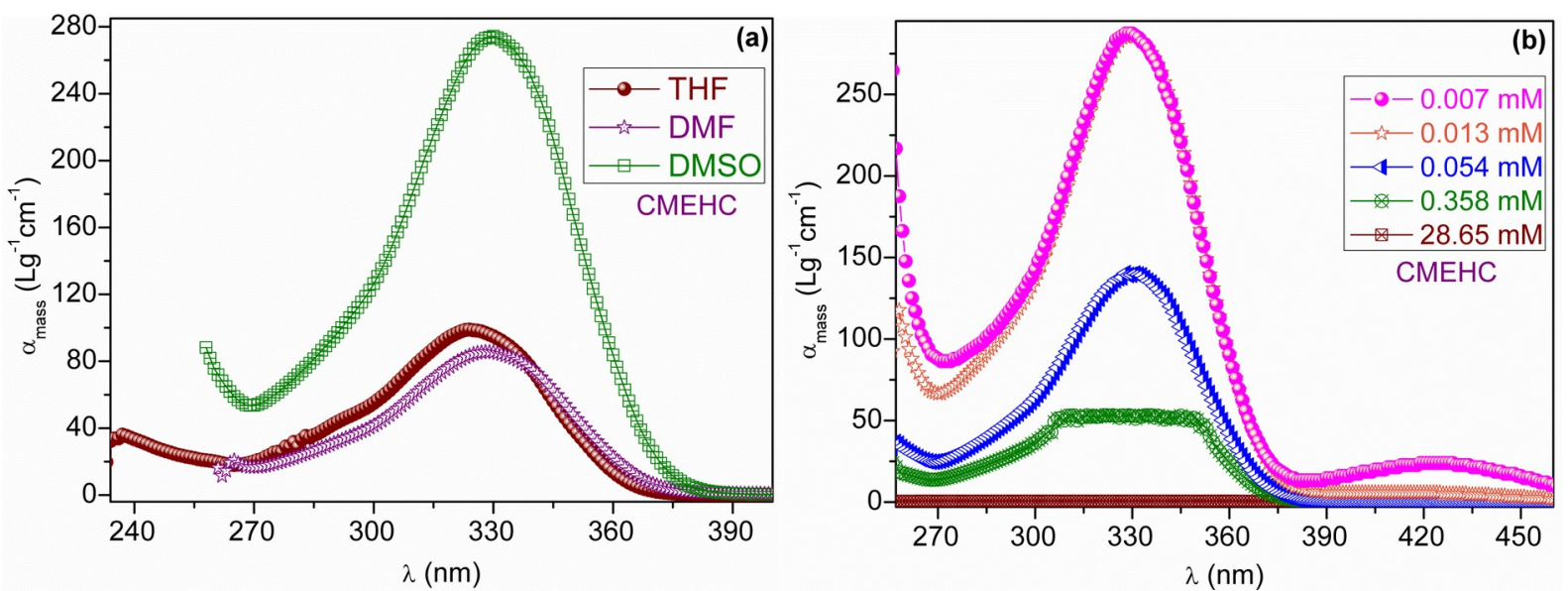

Figure 4. The mass extinction coefficient ( $\left.\alpha_{\text {mass }}\right)$ plot vs. wavelength $(\lambda)$ (a) for THF, DMF and DMSO and (b) for $28.65,0.358,0.054,0.013$ and $0.007 \mathrm{mM}$ in DMSO.

The mass extinction coefficient ( $\left.\alpha_{\text {mass }}\right)$ is investigated for optoelectronic applications and is given in (18, 24).

$$
\alpha_{\text {mass }}=\frac{\mathrm{Abs}}{C \times l \times M_{A}}
$$

where Abs is the absorbance, $\mathrm{C}$ is the molar concentration, $l$ is the length of the optical path of the used cylindrical bathtub and $M_{A}$ is the molecular mass. The $M_{A}$ values of the CMEHC is $210.560 \mathrm{~g} / \mathrm{mol}$. The $\alpha_{\text {mass }}$ values of the CMEHC for different solvents and molarities were calculated from Eq. (1). Figure $4(a, b)$ shows the plots of the $\alpha_{\text {mass }}$ vs. wavelength $(\lambda)$ of the CMEHC for THF, DMF and DMSO solvents and for the concentrations of 28.65, 0.358, 0.054, 0.013 and $0.007 \mathrm{mM}$, respectively. As seen in Figure $4 \mathrm{a}$, the highest $\alpha_{\text {mass }}$ value of the CMEHC is calculated as $274.296 \mathrm{Lg}^{-1} \mathrm{~cm}^{-1}$ for DMSO solvent and it varies with solvents. In Figure $4 \mathrm{~b}$, the $\alpha_{\text {mass }}$ of the CMEHC increases with decreasing molarities, and the highest $\alpha_{\text {mass }}$ value of which is found to be 287.264 $\mathrm{Lg}^{-1} \mathrm{~cm}^{-1}$ at $0.007 \mathrm{mM}$.

The transmittance ( $T$ ) spectra of the CMEHC for THF, DMF and DMSO solvents are shown in Figure $5 a$ where the transmittance values of the CMEHC are at high levels in the visible region while they have pits in the NUV region and vary with solvents. The $T$ spectra of the CMEHC for 28.65, 0.358, 0.054, 0.013 and $0.007 \mathrm{mM}$ are shown in Figure $5 \mathrm{~b}$. As seen in Figure $5 \mathrm{~b}$, the transmittance of the CMEHC continuously increases with decreasing molarity, and after about from $325 \mathrm{~nm}$ to $390 \mathrm{~nm}$, the transmittance sharply increases.
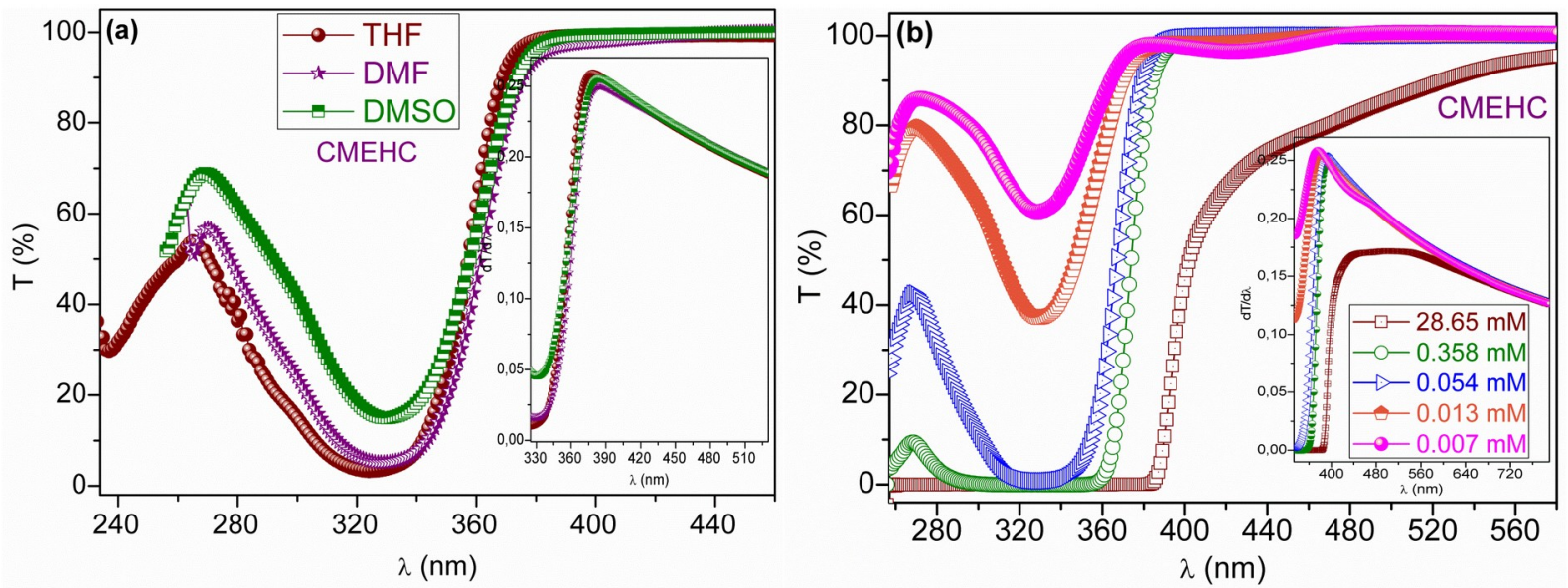

Figure 5. The transmittance (T) spectra: (a) for THF, DMF and DMSO solvents and (b) for 28.65, 0.358 , $0.054,0.013$ and $0.007 \mathrm{mM}$ in DMSO. 
Table 1. The maximum peak position $\left(\lambda_{\max }\right)$, absorption band edge $\left(E_{\text {abs-be }}\right)$, and direct allowed bandgap ( $\left.E_{g d}\right)$ parameters for different solvents (a) and molarities (b) of CMEHC.

\begin{tabular}{lllll}
\hline & Solvents & $\boldsymbol{\lambda}_{\max }(\mathbf{n m})$ & $\mathbf{E}_{\text {Abs-be }}(\mathbf{e V})$ & $\mathbf{E}_{\mathbf{g d}}(\mathbf{e V})$ \\
\cline { 2 - 4 } (a) & THF & 384 & 3.229167 & 3.295 \\
& DMSO & 383 & 3.237598 & 3.313 \\
& DMF & 379 & 3.271768 & 3.357 \\
\hline & Molarities (mM) & $\boldsymbol{\lambda}_{\max }(\mathbf{n m})$ & $\mathbf{E}_{\text {Abs-be }}(\mathbf{e V})$ & $\mathbf{E}_{\mathbf{g d}}(\mathbf{e V})$ \\
(b) & 28.65 & 459 & 2.702 & 2.778 \\
& 0.358 & 395 & 3.139 & 3.202 \\
& 0.054 & 389 & 3.188 & 3.238 \\
& 0.013 & 380 & 3.263 & 3.319 \\
& 0.007 & 376 & 3.298 & 3.355 \\
\hline
\end{tabular}

To determine the absorption band edge ( $\left.E_{\text {Abs-be }}\right)$ values of the CMEHC, we plotted the first derivative $(d T / d \lambda)$ vs. $\lambda$. The $E_{A b s-b e}$ values of the $C M E H C$ for THF, DMF and DMSO solvents and for 28.65, 0.358, $0.054,0.013$ and $0.007 \mathrm{mM}$ are calculated from the maximum peak position $\left(\lambda_{\max }\right)$ of the $\mathrm{dT} / \mathrm{d} \lambda$ plots $\mathrm{vs.}$ $\lambda$ as seen in insets of Figs. $5(a, b)$, respectively. The $\lambda_{\max }$ and $E_{\text {Abs-be }}$ values of the CMEHC coumarin compound for THF, DMF and DMSO solvents and for $28.65,0.358,0.054,0.013$ and $0.007 \mathrm{mM}$ are given in Table $1(a, b)$. As seen in Table $1 a$, the $E_{\text {Abs-be }}$ value (3.229 eV) of the CMEHC for THF is the lowest, while the $E_{\text {Abs-be }}$ value (3.272 eV) of the CMEHC for DMF is the highest. As seen in Table $1 b$, the $E_{\text {Abs-be }}$ of the CMEHC increases with decreasing molarity and varies from 2.702 to $3.298 \mathrm{eV}$.

The optical bandgap $\left(E_{g}\right)$ is a fundamental optical parameter, and the $E_{g}$ of optical transitions can be obtained using Tauc relation $(25,26)$;

$$
(\alpha h v)=A\left(h v-E_{g}\right)^{n}
$$

where $\alpha$ is absorption coefficient, $\mathrm{A}$ is a constant, hv is photon energy, and $\mathrm{n}$ is a parameter, which measures the type of bandgaps. For CMEHC, the type of bandgap (26) is the direct allowed bandgap $\left(E_{g d}\right)$. For this, we plotted the $(\alpha h v)^{2}$ plot vs $E$ of the CMEHC for THF, DMF and DMSO solvents and for $28.65,0.358,0.054,0.013$ and $0.007 \mathrm{mM}$ as seen in Figure $6(a, b)$. We calculated the $E_{g d}$ values from the linear regions of the Figure $6(a, b)$ and obtained $E_{g d}$ values of the CMEHC for THF, DMF, and DMSO solvents and also for 28.65, 0.358, 0.054, 0.013 and $0.007 \mathrm{mM}$ were given in Table $1(\mathrm{a}, \mathrm{b})$. As seen in Table $1 a$, the $E_{\text {gd }}$ value (3.295 eV) of the CMEHC for THF is the lowest while the $E_{g d}$ value $(3.357 \mathrm{eV}$ ) of the CMEHC for DMF is the highest. As seen in Table $1 \mathrm{~b}$, the $\mathrm{E}_{\mathrm{gd}}$ value $(2.778 \mathrm{eV})$ of the CMEHC for 28.65 $\mathrm{mM}$ is the lowest while the $E_{g d}$ value (3.355 eV) of the CMEHC for $0.007 \mathrm{mM}$ is the highest. Obtained these results show that the lowest direct allowed bandgap of the CMEHC can be obtained with THF solvent and the $E_{g d}$ is decreased with increasing molarity.
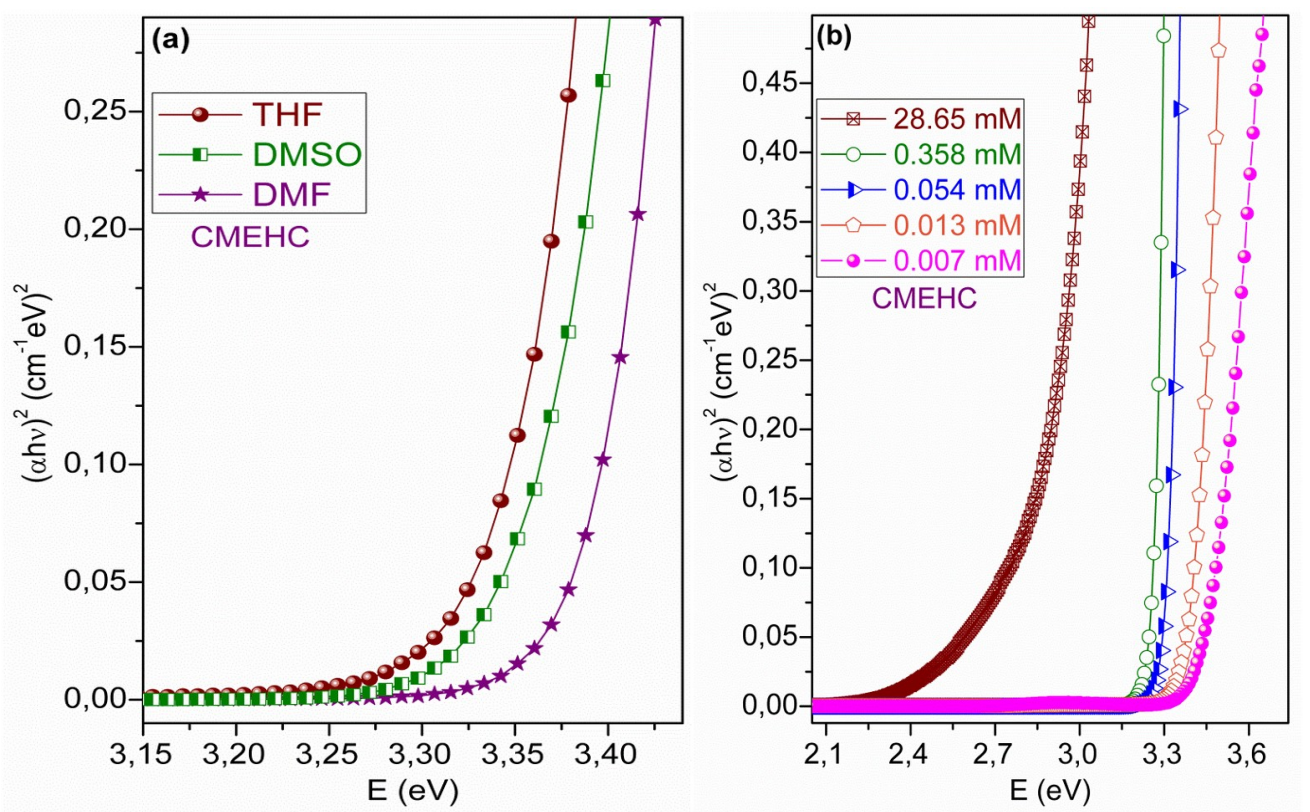

Figure 6. The $(\alpha h v)^{2}$ plot vs. photon energy (E): (a) for THF, DMF and DMSO solvents and (b) for 28.65, $0.358,0.054,0.013$ and $0.007 \mathrm{mM}$ in DMSO. 
Table 2. The refractive index $(n)$ parameters obtained from experimental (Exp) results, Moss (M), Ravindra $(\mathrm{Ra})$, Herve-vandamme (H-V), Reddy (Re) and Kumar-Singh (K-S) relations for different solvents (a) and molarities (b) of the CMEHC.

\begin{tabular}{llllllll}
\hline \multirow{2}{*}{ (a) } & Solvents & Exp & M & Ra & H-V & Re & K-S \\
\cline { 2 - 8 } & THF & 2.174 & 2.317 & 2.0411 & 2.245 & 2.693 & 2.292 \\
& DMSO & 2.099 & 2.314 & 2.030 & 2.241 & 2.688 & 2.288 \\
& DMF & 2.023 & 2.306 & 2.003 & 2.229 & 2.679 & 2.279 \\
\hline \multirow{3}{*}{ (b) } & Molarities (mM) & Exp & $\mathbf{M}$ & $\mathbf{R a}$ & $\mathbf{H - V}$ & $\mathbf{R e}$ & K-S \\
\cline { 2 - 8 } & $\mathbf{2 8 . 6 5}$ & 2.532 & 2.418 & 2.362 & 2.395 & 2.827 & 2.422 \\
& 0.358 & 2.242 & 2.334 & 2.099 & 2.271 & 2.714 & 2.314 \\
& 0.054 & 2.293 & 2.327 & 2.076 & 2.261 & 2.706 & 2.305 \\
& 0.013 & 2.289 & 2.313 & 2.026 & 2.239 & 2.687 & 2.287 \\
& 0.007 & 2.269 & 2.307 & 2.004 & 2.230 & 2.679 & 2.279 \\
\hline
\end{tabular}

The refractive index or index of refraction $(n)$ is a fundamental optical parameter for optoelectronic applications. The $\mathrm{n}$ values can be obtained by $(16,24)$.

$$
n=\left\{\left[\frac{4 R}{(R-1)^{2}}-k^{2}\right]^{1 / 2}-\frac{R+1}{R-1}\right\}
$$

The $n$ values calculated experimentally of the CMEHC compound for THF, DMF, and DMSO solvents and for 28.65, 0.358,0.054, 0.013, and $0.007 \mathrm{mM}$ were given in Table 2(a,b). As seen in Table 2(a,b), the lowest refractive index of the CMEHC can be obtained with DMF solvent and the $n$ of the CMEHC is decreased with decreasing molarity.

The relation between the optical bandgap and refractive index can be explained with many relations such as Moss, Ravindra, Herve-vandamme, Reddy, and Kumar-Singh (27). These are represented in the following equations:

Moss relation is given by:

$$
n=\left(\frac{95}{E_{g}(e V)}\right)^{1 / 4}
$$

Ravindra relation is given by:

$$
n=4.084-0.62 E_{g}
$$

Herve-vandamme relation is given by:

$$
n^{2}=1+\left(\frac{A}{E_{g}+B}\right)^{2}
$$

where $A$ is the hydrogen ionization energy $13.6 \mathrm{eV}$ and $\mathrm{B}=3.47 \mathrm{eV}$ is a constant.

Reddy relation is given by:

$$
n=\left(\frac{154}{\left(E_{g}-0.365\right)}\right)^{1 / 4}
$$

Kumar-Singh relation is given by

$$
n=\frac{3.3688}{E_{g}^{0.32234}}
$$

Consequently, the refractive index values of the CMEHC were obtained from experimental results of Moss, Ravindra, Herve-vandamme, Reddy, and Kumar-Singh relations. The refractive index curves derived from these equations for CMEHC compound in different solvents (THF, DMF, DMSO) and concentrations $(28.65,0.358,0.054,0.013,0.007$ $\mathrm{mM}$ ) were illustrated in Figure $7(\mathrm{a}, \mathrm{b})$. Their values were also given in Table $2(a, b)$. As seen in Table $2(a, b)$, the $n$ values of the CMEHC obtained for THF solvent and from Reddy relation are the highest, while the $n$ values of the CMEHC obtained for DMF solvent and from Ravindra relation are the lowest. Obtained results suggest that the related solvents have a higher effect on the refractive index of the CMEHC and also the refractive index can be controlled with different solvents and molarities. 

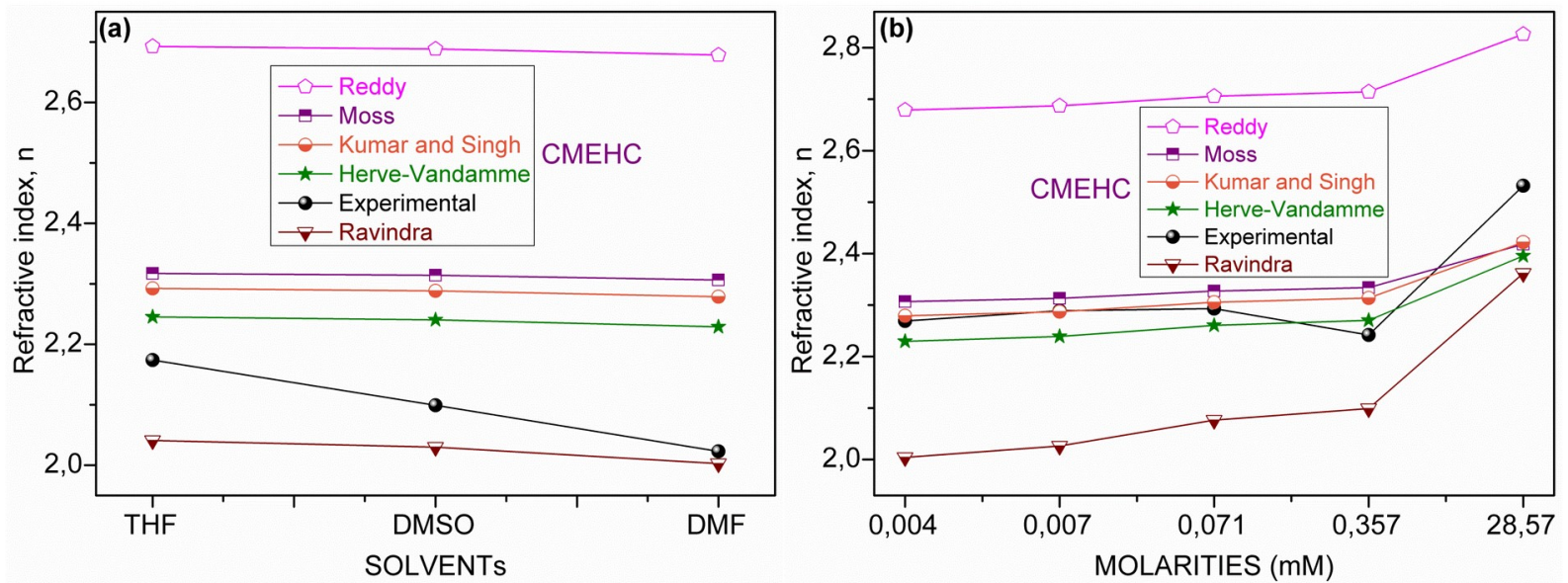

Figure 7. The refractive index plots obtained from various relations (a) for THF, DMF and DMSO solvents and (b) for 28.65, 0.358, 0.054, 0.013 and $0.007 \mathrm{mM}$ in DMSO.

\section{CONCLUSION}

Effects of the solvents and molarities on the optical properties of the CMEHC coumarin compound were investigated. The absorbance spectra of the CMEHC are dominant in the NUV region. The mass extinction coefficient of the CMEHC increases with decreasing molarities. THF, DMF and DMSO solvents have a role in the absorption band edge of the CMEHC compound. The lowest direct allowed bandgap can be obtained with THF solvent. The $E_{g d}$ of the CMEHC is also decreased with increasing molarity. The lowest refractive index can be obtained with DMF solvent, and the $n$ of the CMEHC is decreased with decreasing molarity. The $n$ values obtained for THF and Reddy relation are the highest whereas those are the lowest values for DMF and Ravindra relation. The obtained results show that 4chloromethyl-7-hydroxy coumarin exhibits a semiconductor behavior and it may be an important candidate for many optoelectronic devices such as diodes, photo-diodes, and sensors.

\section{REFERENCES}

1 Sahoo SS., Shukla S, Nandy S, Sahoo HB. Synthesis of Novel Coumarin Derivatives and its Biological Evaluations. European Journal of Experimental Biology. 2012;2(4):899-908.

2 Skowronski L, Krupka O, Smokal V, Grabowski A, Naparty M, Derkowska-Zielinska B. Optical properties of coumarins containing copolymers. Optical Materials. 2015;47:18-23.

3 Olayinka AO, Obinna NC. Microwave-assisted synthesis and evaluation of antimicrobial activity of 3-\{3-(s-aryl and s-heteroaromatic)acryloyl $\}-2 \mathrm{H}-$ chromen-2-one derivatives. Journal of Heterocyclic Chemistry. 2010;47(1):179-87.

4 Brahnbhatt DI, Gajera JM, Pandya VP, Patel MA. Synthesis of 3-(6-aryl-pyridin-2-yl)- and 8-(6- aryl-pyridin-2-yl) coumarins. Indian Journal of Chemistry. 2007;46(B):869-71.

5 Tasior $M$, Kim D, Singha S, Krzeszewski M, Ahn KH, Gryko DT. pi-Expanded coumarins: synthesis, optical properties and applications. Journal of Materials Chemistry C. 2015;3:1421-46.

6 Swanson SA, Wallraff GM, Chen JP, Zhang WJ, Bozano LD, Carter KR, Salem JR, Villa R, Scott JC. Stable and Efficient Fluorescent Red and Green Dyes for External and Internal Conversion of Blue OLED Emission. Chemistry of Materials. 2003;15(12):230512.

7 Zhang H, Yu T, Zhao Y, Fan D, Qian L, Yang C, Zhang K. Syntheses, characterization and fluorescent properties of two triethylene-glycol dicoumarin-3-carboxylates. Spectrochimica Acta Part A: Molecular and Biomolecular Spectroscopy. 2007;68(3):725-27.

8 Jones G, Rahman MA, Fluorescence properties of coumarin laser dyes in aqueous polymer media. chromophore isolation in poly(methacrylic acid) hypercoils. J. Phys. Chem., 1994;98(49):13028-37.

9 Gindre D, lliopoulos K, Krupka O, Evrard M, Champigny $E$, Sallé $M$. Coumarin-Containing polymers for high density non-linear optical data storage. Molecules, 2016;21(2):147.

10 Kim C, Trajkovska A, Wallace JU, Chen SH. New insight into photoalignment of liquid crystals on coumarin-containing polymer films. Macromolecules. 2006;39 (11):3817-23.

11 Donovalova J, Cigan $M$, Stankovicova $H$, Gaspar J, Danko M, Gaplovsky A, Hrdlovic P. Spectral properties of substituted coumarins in solution and polymer matrices. Molecules. 2012;17:3259-76. 
12 Gindre D, lliopoulos K, Krupka O, Champigny $E$, Morille $Y$, Sallé $M$. Image storage in coumarinbased copolymer thin films by photoinduced dimerization. Optics Letters. 2013;38(22):4636-9.

13 Chen W, Tong US, Zeng T, Streb C, Song YF. Reversible photodimerization of coumarin-modified Wells-Dawson anions. Journal of Materials Chemistry C 2015;3:4388-93.

14 Bakhtiari G, Moradi S, Soltanali S. A novel method for the synthesis of coumarin laser dyes derived from 3-(1H-benzoimidazol-2-yl) coumarin-2one under microwave irradiation. Arabian Journal of Chemistry. 2014;7(6):972-5.

15 Liu X, Xu Z, Cole JM. Molecular design of UV-vis absorption and emission properties in organic fluorophores: toward larger bathochromic shifts, enhanced molar extinction coefficients, and greater stokes shifts. The Journal of Physical Chemistry C. 2013;117(32);16584-95.

16 Kurt $A$. Influence of $\mathrm{AlCl}_{3}$ on the optical properties of new synthesized 3-armed poly(methyl methacrylate) films. Turkish Journal of Chemistry.2010;34(1):67-69.

17 Kurt A, Koca M. Blending of poly(ethyl methacrylate) with poly(2-hydroxy-3-phenoxypropyl methacrylate): thermal and optical properties. The Arabian Journal for Science and Engineering. 2014;39:5413-20.

18 Gunduz B. Investigation of the spectral, optical and surface morphology properties of the $\mathrm{N}, \mathrm{N}$ '-Dipentyl-3,4,9,10-perylenedicarboximide small molecule for optoelectronic applications. Polymers For Advanced Technologies. 2016;27:144-55.

19 Gunduz B. Surface morphology properties of the 5,5'-di(4-biphenylyl)-2,2'-bithiophene (PPTTPP) nanofiber film and calculations of the optical parameters of the PPTTPP nanofiber optoelectronic devices. Journal of Nanoelectronics and Optoelectronics. 2015;10(1):1-8.
20 Bai $Y$, Du J, Weng $X$. Synthesis, characterization, optical properties and theoretical calculations of 6-fluoro coumarin. Spectrochimica Acta Part A: Molecular and Biomolecular Spectroscopy. 2014;126:14-20.

21 Rabahi A, Makhloufi-Chebli M, Hamdi SM, Silva AMS, Kheffache D, Kheddis BB, Hamdi $M$. Synthesis and optical properties of coumarins and iminocoumarins: Estimation of ground- and excitedstate dipole moments from a solvatochromic shift and theoretical methods. Journal of Molecular Liquids. 2014;195:240-7.

22 Abd-El-Aziz AS, Mohamed HM, Mohammed S, Zahid S, Ata A, Bedair AH, El-Agrody AM, Harvey PD. Synthesis of novel coumarin and benzocoumarin derivatives and their biological and photophysical studies. Journal of Heterocyclic Chemistry, 2007;44:1287-1301.

23 Kurt A, Kaya M, Koca M. Synthesis and characterization of coumarin derived surface active monomer. Adıyaman University Journal of Science. 2016; 6:110-21.

24 Gündüz B. Optical properties of poly[2methoxy-5-(3', 7'-dimethyloctyloxy)-1,4-

phenylenevinylene] light-emitting polymer solutions: effects of molarities and solvents. Polymer Bulletin. 2015;72(12):3241-67.

25 Tauc J. Amorphous and Liquid Semiconductors, Plenum Press, New York, 1974.

26 Gündüz B. Effects of molarity and solvents on the optical properties of the solutions of tris[4-(5dicyanomethylidenemethyl-2-thienyl)phenyl]amine (TDCV-TPA) and structural properties of its film. Optical Materials. 2013;36(2):425-36.

27 Tripathy SK. Refractive indices of semiconductors from energy gaps. Optical Materials. 2015;46:240-46. 